\title{
Primary hyperparathyroidism due to a cystic parathyroid adenoma in a cat
}

\author{
Anaïs Lamoureux ${ }^{1, *}$, Alexandre Fournet ${ }^{2}$, Harriet M. Hahn ${ }^{3}$, Quentin Pascal ${ }^{4}$, Eve Laloy ${ }^{4}$, Mathieu Manassero ${ }^{2}$ and \\ Miguel Campos ${ }^{5}$ \\ ${ }^{1}$ Unité de médecine interne, Ecole Nationale Vétérinaire d'Alfort, UPEC, Maisons-Alfort F-94700, France \\ ${ }^{2}$ Unité de chirurgie, Ecole Nationale Vétérinaire d'Alfort, UPEC, Maisons-Alfort F-94700, France \\ ${ }^{3}$ Unité d'imagerie médicale, Ecole Nationale Vétérinaire d'Alfort, UPEC, Maisons-Alfort F-94700, France \\ ${ }^{4}$ Unité d'anatomie pathologique, Ecole Nationale Vétérinaire d'Alfort, Biopôle d'Alfort, Maisons-Alfort F-94700, \\ France \\ ${ }^{5}$ U955-IMRB, Inserm, Unité de médecine interne, Ecole Nationale Vétérinaire d'Alfort, UPEC, Maisons-Alfort \\ F-94700, France
}

\begin{abstract}
A 15-year-old neutered female domestic shorthair cat was presented for weight loss, polydipsia/polyuria, and lethargy. A large fluctuant mass was palpated in the ventral right cervical region. Biochemistry results were consistent with primary hyperparathyroidism. Parathyroid hormone level in the fluid was higher to that observed in the plasma, consistent with a cystic parathyroid lesion. Right parathyroidectomy and thyroidectomy were performed without complications. Ionized calcium normalized within a few hours. Histopathology yielded a diagnosis of cystic parathyroid adenoma. Follow-up showed complete recovery of clinical signs and normalization of ionized calcium. This case shows an uncommon presentation of feline primary hyperparathyroidism secondary to a cystic parathyroid adenoma and is, to our knowledge, the first case presented with a large palpable mass in which parathyroid hormone concentration was measured. This report highlights the value of selective hormonal analyses of the cystic fluid to confirm the origin of the cystic lesion pre-operatively.
\end{abstract}

Keywords: Adenoma, Calcium, Cyst, Hyperparathyroidism, Parathyroid hormone.

\section{Introduction}

Functional parathyroid lesions are very uncommon in cats and most proliferative parathyroid lesions are classified as adenomas while parathyroid carcinoma and hyperplasia are rarely found (Feldman, 2010). Parathyroid cystic tumors in cats have rarely been reported in the veterinary literature (Kallet et al., 1991; Phillips et al., 2003; Cavana et al., 2006). In humans, cystic parathyroid lesions are unusual with less than 300 cases reported (McCoy et al., 2009; Dutta et al., 2013).

\section{Case Details}

A 15-year-old neutered female domestic shorthair cat weighting $3.8 \mathrm{~kg}$ was presented for weight loss despite normal appetite, polyuria, and polydipsia (PUPD) for $3 \mathrm{yr}$ and lethargy for $1 \mathrm{mo}$. On physical examination, the cat was underweight (body condition score 3/9) and had small irregular kidneys. A large $(7 \times 5 \mathrm{~cm})$, fluctuant, non-painful mass was present in the ventral right cervical region (Fig. 1).

Differential diagnosis for a fluid-filled mass in the cervical region includes a cyst of thyroid, parathyroid, branchial, ultimobranchial or dermoid origin, necrotic neoplasia, salivary mucocele, and abscess (Capen,
2002; Phillips et al., 2003; Tolbert et al., 2009; Nelson et al., 2012).

Blood biochemistry revealed mild azotemia and mild ionized hypercalcemia (Table 1). Serum phosphorus and total thyroxine were within reference range. Serum parathyroid hormone $(\mathrm{PTH})$ concentration, measured at the same time as ionized calcium concentration, was in the upper half of the reference range. Given the absence of severe azotemia, these findings were consistent with primary hyperparathyroidism (Kruger et al., 1996; Geddes et al., 2013; Parker et al., 2015). Urinalysis revealed a specific gravity of 1.016 , compatible with the reported PUPD. Findings of azotaemia, isosthenuria, and small irregular kidneys were consistent with chronic kidney disease.

Radiographs of the neck and thorax were performed (Fig. 2). Cervical ultrasonography identified an anechoic fluid-filled structure with distal enhancement, delimitated by a thin wall, on the right side of the trachea, consistent with a cyst. A significant amount $(40 \mathrm{ml})$ of yellow-brown, thick fluid was aspirated. Cytological examination was inconclusive. Total thyroxine concentration in the cystic fluid was low $(12.9 \mathrm{nmol} / \mathrm{l})$. The PTH concentration was above $2,000 \mathrm{pg} / \mathrm{ml}$. On the basis of these findings, the cystic mass was diagnosed 
as having a parathyroid origin and was suspected to be the cause of primary hyperparathyroidism.

Parathyroidectomy was recommended. In order to plan surgery, a computed tomography (CT) of the cervical

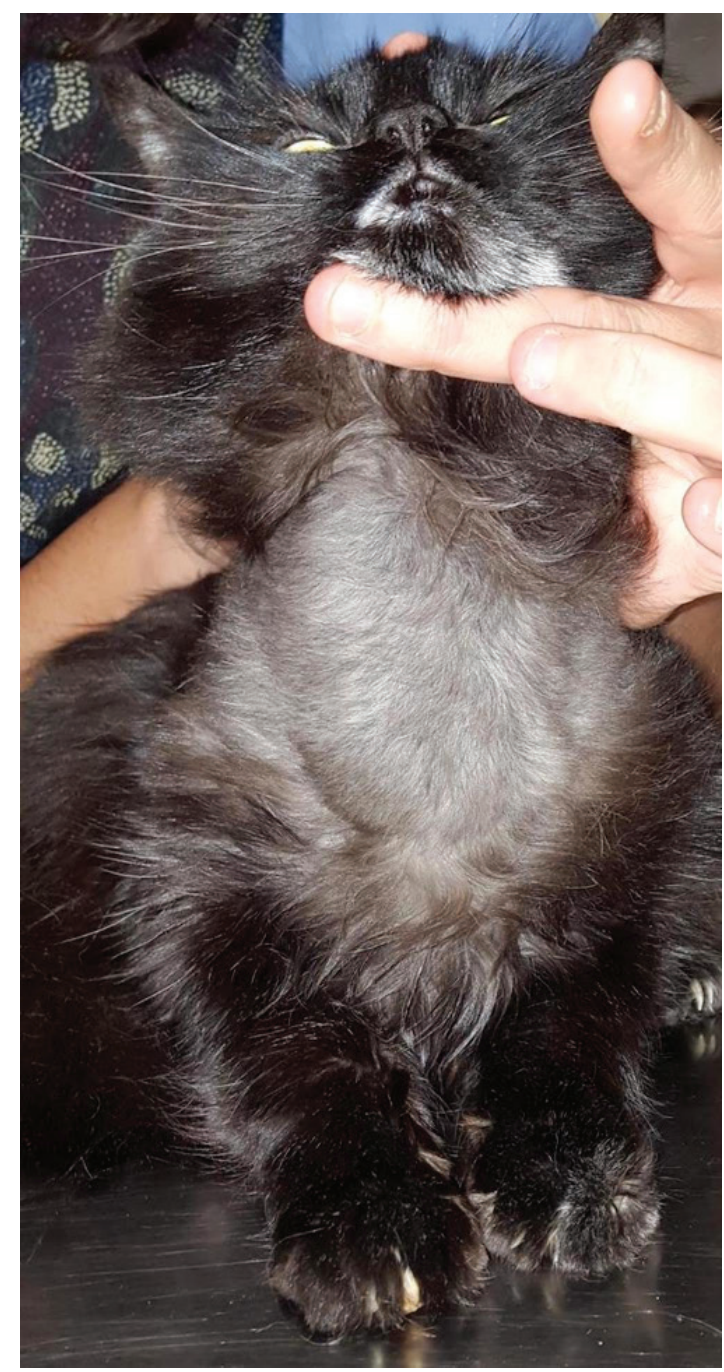

Fig. 1. Photograph of the cat presented with a large mass in the ventral right cervical region. region was performed under general anesthesia, using a 64-slice helical CT scanner (Brilliance, 64-slice; Phillips) and contrast media (iohexol) (Fig. 3A and B). For the surgical procedure, the patient was placed in dorsal recumbency and the area was aseptically prepared. A ventral midline skin incision was made from the larynx to the manubrium. The right sternocephalic and sternohyoidus muscle were retracted medially. A well-encapsulated mass was visualized, directly adjacent to the trachea and the thyroid gland (Fig. 4). No adherences to surrounding structures were observed. Dissection and hemostasis were performed with a vessel sealer/divider device (LigaSure Atlas; Valleylab; Covidien; Vetoquinol) and the mass was marginally excised with the right thyroid gland. Incisions were closed routinely.

The cat recovered well and showed no clinical signs of hypocalcaemia. Within $14 \mathrm{~h}$, ionized calcium concentration normalized (Table 1). The cat was discharged $2 \mathrm{~d}$ after surgery.

Histopathology of the mass was consistent with a cystic parathyroid adenoma (Fig. 5). The lesion was composed of rows of epithelial cells separated by a thin fibrovascular stroma. Some neoplastic cells formed single layer cysts. The cells were polygonal, with a moderately abundant, lightly to intensely eosinophilic cytoplasm, and with central ovoid nucleus with stippled chromatin and a small nucleolus. The cells displayed mild anisocytosis and anisokaryosis with less than 1 mitosis per high-power field.

Upon re-evaluations in the following year, the cat was doing well with an improvement, albeit not resolution, of the PUPD. Ionized calcium remained within reference interval and azotaemia was stable (Table 1). A renal diet was prescribed. The cat was euthanized 2.5 yr later following an acute onset of neurological signs.

\section{Discussion}

This case report is the second description of a functional cystic parathyroid adenoma in a cat and is, to the authors' knowledge, the first presented with a large, palpable, unilateral cervical mass in which PTH concentration was measured in the cystic fluid confirming its origin (Kallet et al., 1991).

Table 1. Blood biochemistry and electrolytes results.

\begin{tabular}{lccccccccc}
\hline Parameters & Units & At presentation & $\begin{array}{c}\text { 14 hours } \\
\text { after } \\
\text { surgery }\end{array}$ & $\begin{array}{c}\text { 2 weeks } \\
\text { after } \\
\text { surgery }\end{array}$ & $\begin{array}{c}\text { 6 weeks } \\
\text { after } \\
\text { surgery }\end{array}$ & $\begin{array}{c}\mathbf{7} \text { months } \\
\text { after } \\
\text { surgery }\end{array}$ & $\begin{array}{c}\mathbf{2 . 5} \text { years } \\
\text { after } \\
\text { surgery }\end{array}$ & $\begin{array}{c}\text { Reference } \\
\text { range }\end{array}$ \\
\hline Ionized calcium & $\mathrm{mmol} / 1$ & 1.58 & 1.23 & 1.28 & 1.28 & 1.27 & 1.33 & $1.1-1.4$ \\
Phosphorus & $\mathrm{mg} / \mathrm{dl}$ & 4.7 & $/$ & $/$ & 5.3 & 4.7 & 6.7 & $3-6$ \\
PTH & $\mathrm{pg} / \mathrm{ml}$ & 130 & $/$ & $/$ & $/$ & $/$ & $/$ & $50-200$ \\
BUN & $\mathrm{mg} / \mathrm{dl}$ & 53 & 43 & 45 & 49 & 42 & 20 & $10-33$ \\
Creatinine & $\mathrm{mg} / \mathrm{dl}$ & 2.4 & 1.6 & 1.8 & 2.0 & 2.3 & 1.5 & $0-2$ \\
Total thyroxine & $\mathrm{nmol} / 1$ & 30.1 & $/$ & $/$ & $/$ & $/$ & $/$ & $10-60$ \\
\hline
\end{tabular}


Determining the origin of a cervical mass is important as it may have implications for treatment (Phillips et al., 2003). While some functional cystic thyroid lesions can be managed medically, surgical excision is considered

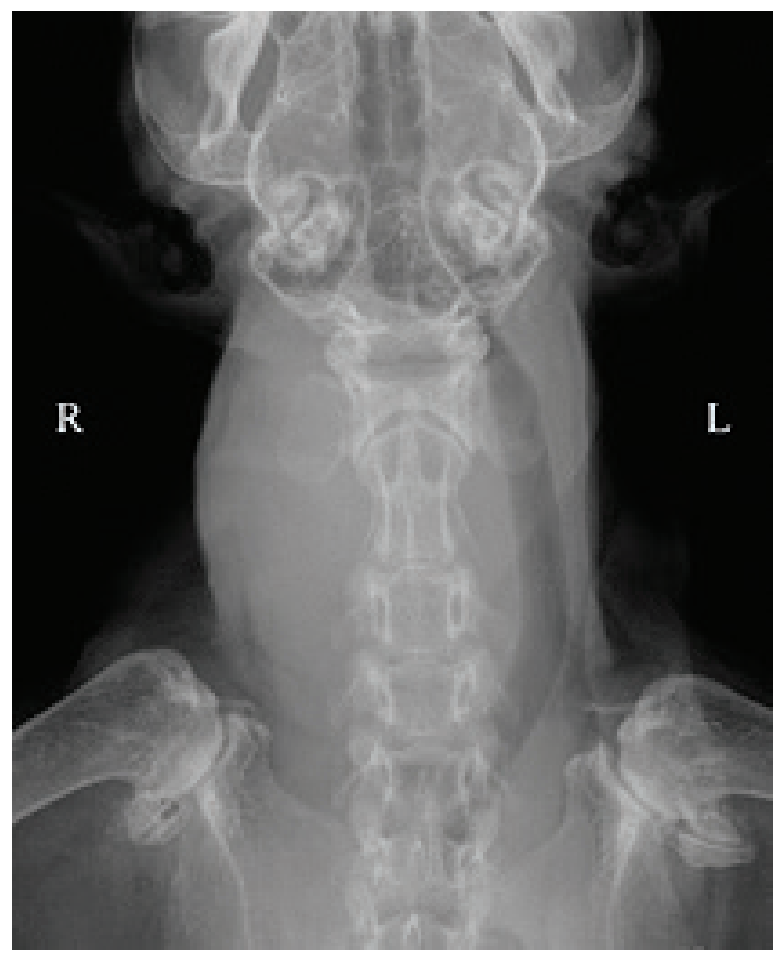

Fig. 2. Ventrodorsal radiography of the neck showing a large homogeneous right cervical soft-tissue mass with marked lateral deviation of the cervical trachea to the left. the treatment of choice for most other lesions, such as functional parathyroid cysts (Pontikides et al., 2012).

The distinction between cystic parathyroid and thyroid lesions can be quite difficult, both lesions may present as asymptomatic cervical masses with occasional signs related to the compression of adjacent structures. Ultrasonography, CT, and 99mTc-MIBI scans can be used but may not differentiate between thyroid and parathyroid cysts (Yalcin et al., 2014). Fine needle aspiration and cytology of cystic fluid is a valuable diagnostic tool but may be inconclusive, such as in the reported case. Parathyroid cysts often contain a clear, watery fluid, whereas thyroid cysts usually contain blood-tinged, brown-colored material (Phillips et al., 2003). However, in the case of functional parathyroid cystic lesions, the aspirate may also be yellowbrown due to a pre-existing degenerated or infracted parathyroid adenoma containing hemosiderin, as observed here (Pontikides et al., 2012). The better tool to establish a diagnosis is to obtain total thyroxine and PTH concentrations in the fluid. Thyroid cystic fluid usually presents high concentrations of total thyroxine and undetectable PTH, whereas in parathyroid cystic lesions (functional and non-functional), PTH concentrations are elevated in the fluid comparatively to serum.

In this case report, the ionized hypercalcemia and serum PTH concentration in the upper half of reference range were consistent with primary hyperparathyroidism, strongly suggesting that the cystic cervical mass was of parathyroid origin. However, confirmation was only possible after hormone measurement in the cystic
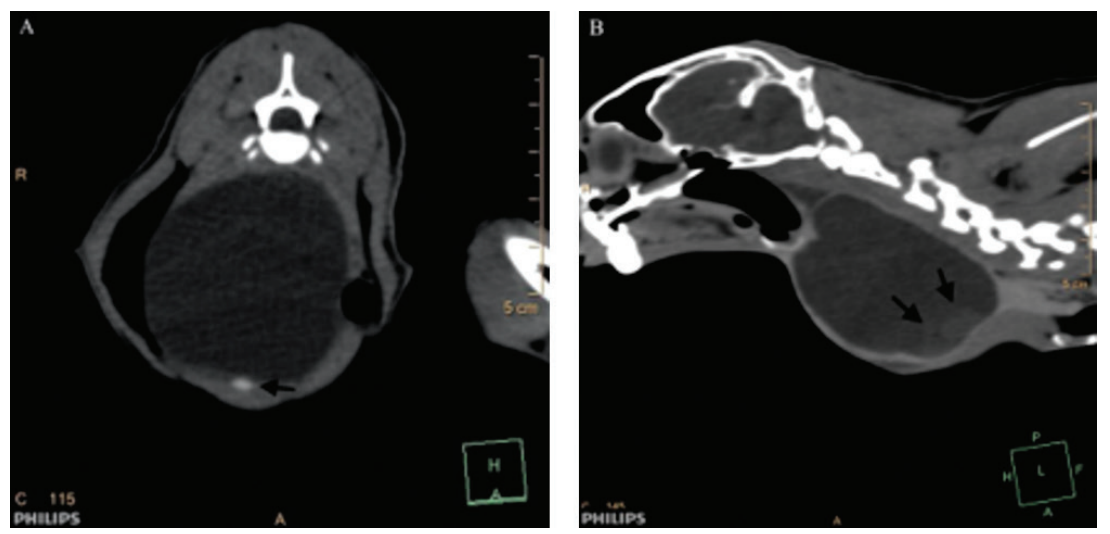

Fig. 3. Transverse (A) and sagittal (B) CT images of the cervical region, respectively, before and after IV contrast media administration, showing a well-defined, nonenhancing fluid-filled mass, surrounded by a thin enhancing wall, measuring $6.4 \mathrm{~cm}$ craniocaudally and $4.2 \mathrm{~cm}$ lateromedially and ventrodorsally, deviating the trachea, esophagus, and surrounding vascular structures to the left. The right lobe of the right thyroid gland was displaced ventrally and caudally and localized along the ventral wall of the mass, in its caudal half (A, arrow). Agglomerated slightly hyperattenuating cellular material was observed in the dependent part of the lumen of the cyst, consistent with a blood clot, likely secondary to the fine-needle aspiration previously performed (B, arrow). No invasion of surrounding structures was observed. 


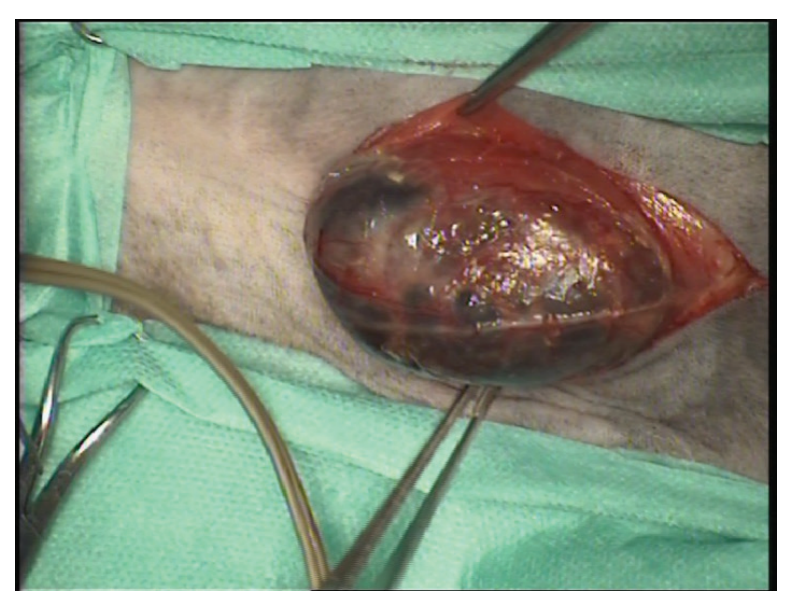

Fig. 4. Photograph of the mass obtained during surgery. The mass is well-encapsulated and measured $8 \mathrm{~cm} \times 5 \mathrm{~cm}$.

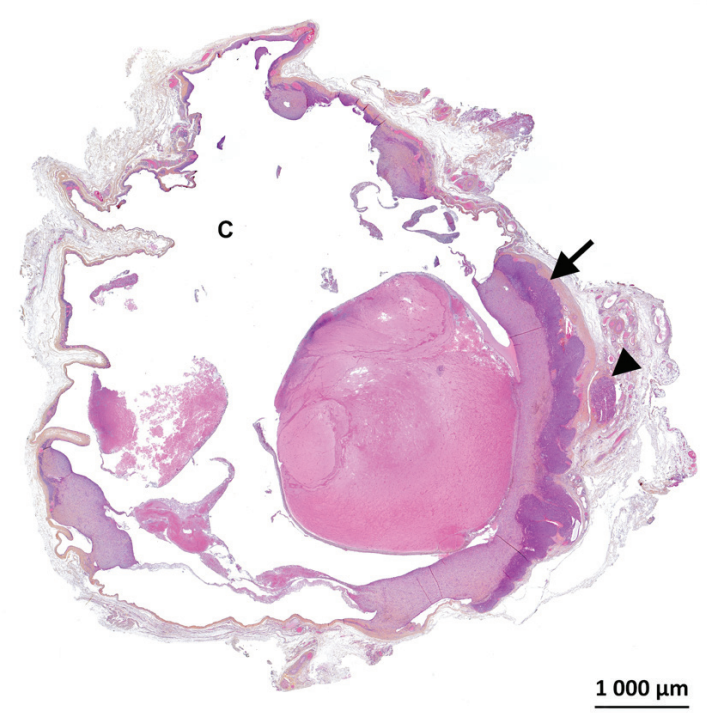

Fig. 5. Microphotograph of the cystic parathyroid adenoma. Within the severely atrophic parathyroid parenchyma, a $2 \mathrm{~cm}$ in diameter encapsulated round cystic tumor with compressive growth was observed. The tumor (arrow) includes a large cyst (C) containing an organizing hematoma. A diffuse atrophy of the right thyroid gland (arrowhead) was observed, consistent with mass compression. Hematoxylineosin-saffron stain, bar $=1,000 \mu \mathrm{m}$.

fluid, as primary hyperparathyroidism could occur concurrently with cystic lesions of other origin.

Surgery was elected because of the functional nature of the parathyroid cystic lesion and because of the size of the mass which compressed the surrounding structures (Pontikides et al., 2012). In dogs, primary hyperparathyroidism has also been treated by ultrasound-guided chemical ablation and ultrasonographically guided radiofrequency heat ablation (Rasor et al., 2007; Guttin et al., 2015).
However, none of the cases described were associated with a cystic lesion.

After surgery, ionized calcium normalized within a few hours and no recurrence of hypercalcemia was observed. Post-operative hypocalcaemia is a common condition reported in dogs and can also be observed in cats after unilateral parathyroidectomy. For this reason, ionized calcium levels should be closely monitored after surgery (Cavana et al., 2006). In humans, serum PTH levels are also monitored during and after surgery (Dutta et al., 2013).

In this case, biochemical analyses revealed primary hyperparathyroidism and mild renal azotaemia. Renal azotaemia may have been the result of concurrent chronic kidney disease or of irreversible structural changes secondary to hypercalcemia (Polzin, 2017).

In conclusion, the case presented here is a very uncommon description of a cystic parathyroid adenoma. This report intends to highlight the importance of preoperative selective hormonal analyses of cystic fluid. Surgical resection of these functional lesions allows a cure. Definitive diagnosis of parathyroid adenoma is based on histopathology results. After the surgery, close monitoring of calcaemia is mandatory.

\section{Conflict of interest}

The authors declare that there is no conflict of interest.

\section{References}

Capen, C.C. 2002. Tumors of the endocrine glands. In Tumors in domestic animal, 4th edn, Eds., Meuten, D.J. Ames, IA, Wiley Blackwell, pp: 607-696.

Cavana, P., Vittone, V., Capucchio, M.T. and Farca, A.M. 2006. Parathyroid adenocarcinoma in a nephropathic Persian cat. J. Feline Med. Surg. 8, 340-344.

Dutta, D., Selvan, C., Kumar, M., Datta, S., Das, R.N., Ghosh, S., Mukhopadhyay, S. and Chowdhury, S. 2013. Needle aspirate PTH in diagnosis of primary hyperparathyroidism due to intrathyroidal parathyroid cyst. Endocrinol. Diabetes Metab. Case Rep. 2013, 130019. doi: 10.1530/EDM-13-0019

Feldman, E.C. 2010. Disorders of the parathyroid glands. In Textbook of veterinary internal medicine, 7th edn. Eds., Ettinger, S.J. and Feldman, E.C. Saunders Elsevier, Saint Louis, MO, pp: 1722-1751.

Geddes, R.F., Finch, N.C., Elliott, J. and Syme, H.M. 2013. Fibroblast growth factor 23 in feline chronic kidney disease. J. Vet. Intern. Med. 27, 234-241.

Guttin, T., Knox, V.W. and Diroff, J.S. 2015. Outcomes for dogs with primary hyperparathyroidism following treatment with percutaneous ultrasoundguided ethanol ablation of presumed functional parathyroid nodules: 27 cases (2008-2011). J. Am. Vet. Med. Assoc. 247, 771-777.

Kallet, A.J., Richter, K.P., Feldman, E.C. and Brum, D.E. 1991. Primary hyperparathyroidism in cats: 
seven cases (1984-1989). J. Am. Vet. Med. Assoc. 199, 1767-1771.

Kruger, J.M., Osborne, C.A., Nachreiner, R.F. and Refsal, K.R. 1996. Hypercalcemia and renal failure. Etiology, pathophysiology, diagnosis, and treatment. Vet. Clin. North Am. Small Anim. Pract. 26, 1417-1445.

McCoy, K.L., Yim, J.H., Zuckerbraun, B.S., Ogilvie, J.B., Peel, R.L. and Carty, S.E. 2009. Cystic parathyroid lesions: functional and nonfunctional parathyroid cysts. Arch. Surg. 144, 52-56.

Nelson, L.L., Coelho, J.C., Mietelka, K. and Langohr, I.M. 2012. Pharyngeal pouch and cleft remnants in the dog and cat: a case series and review. J. Am. Anim. Hosp. Assoc. 48, 105-112.

Parker, V.J., Gilor, C. and Chew, D.J. 2015. Feline hyperparathyroidism. Pathophysiology, diagnosis and treatment of primary and secondary disease. J. Feline Med. Surg. 17, 427-439.

Phillips, D.E., Radlinsky, M.G., Fischer, J.R. and Biller, D.S. 2003. Cystic thyroid and parathyroid lesions in cats. J. Am. Anim. Hosp. Assoc. 39, 349-354.
Polzin, D.J. 2017. Chronic kidney disease. In Textbook of veterinary internal medicine, 8th edn. Eds., Ettinger, S.J., Feldman, E.C. and Côté, E. Elsevier, Saint Louis, MO, pp: 1938-1959.

Pontikides, N., Karras, S., Kaprara, A., Cheva, A., Doumas, A., Botsios, D., Moschidis, A., Efthumiou, E., Wass, J. and Krassas, G. 2012. Diagnostic and therapeutic review of cystic parathyroid lesions. Hormones (Athens) 11, 410-418.

Rasor, L., Pollard, R. and Feldman, E.C. 2007. Retrospective evaluation of three treatment methods for primary hyperparathyroidism in dogs. J. Am. Anim. Hosp. Assoc. 43, 70-77.

Tolbert, K., Brown, H.M., Rakich, P.M., Radlinsky, M.A.G. and Ward, C.R. 2009. Dermoid cysts presenting as enlarged thyroid glands in a cat. J. Feline Med. Surg. 11, 717-719.

Yalcin, Y., Mete, T., Aktimur, R., Kucuk, G.O., Duman, G., Ozbalci, A.B. and Alici, O. 2014. A case of primary hyperparathyroidism due to intrathyroidal parathyroid cyst. Case Rep. Endocrinol. 2014, 213283. doi: $10.1155 / 2014 / 213 / 283$ 